\title{
The Extent to which Mobile Applications Support Independence among the Visually Impaired - A Pilot Study
}

Järvelä ${ }^{a^{*}}$ M.E., Falck ${ }^{b}$ A. A. K., Rajala ${ }^{a}$ M., Kyngäs H.A. and Siira ${ }^{a}$ H. J.

${ }^{a}$ Research Unit of Nursing Science and Health Management, University of Oulu, Oulu, Finland; ${ }^{b}$ Department of Ophthalmology, Medical Research Center and PEDEGO Research Unit, University of Oulu and Oulu University Hospital, Oulu, Finland

Milla Emilia Järvelä, Research Unit of Nursing Science and Health Management, University of Oulu, PO BOX 5000, 90014 University of Oulu, Finland, e-mail: jarvela.milla@gmail.com, tel. +358405363962, LinkedIn: Milla Järvelä

Aura Aino Kaarina Falck, Department of Ophthalmology, Medical Research Center and PEDEGO Research Unit, University of Oulu and Oulu University Hospital, PL 21, 90029 OYS, ORCiD: 0000-0002-1762-0228, e-mail: aura.falck@ ppshp.fi, tel. +3583153367

Mira Maaret Rajala, Research Unit of Nursing Science and Health Management, Medical Research Center, University of Oulu and Oulu University Hospital, PO BOX 5000, 90014 University of Oulu, Finland. ORCid: 0000-0002-1096-5530, e-mail: mira.rajala@oulu.fi, tel. + 358504407657, Twitter: @MiraRajala1

Helvi Aulikki Kyngäs, Research Unit of Nursing Science and Health Management, University of Oulu, PO BOX 5000, 90014 University of Oulu, Oulu University Hospital, Finland, ORCiD: 0000-0002-5723-3484 tel.+358504530121, helvi.kyngas@oulu.fi

Heidi Johanna Siira, Research Unit of Nursing Science and Health Management, Medical Research Center and Department of Ophthalmology, University of Oulu and Oulu University Hospital, PO BOX 5000, 90014 University of Oulu, Finland, ORCiD: 0000-0001-8707-0164, email: heidi.siira@oulu.fi, tel.+358504308210, Twitter: @SiiraHeidi, LinkedIn: Heidi Siira 


\section{The Extent to which Mobile Applications Support Independence among the Visually Impaired - A Pilot Study}

Background and aim: Visual impairment (VI) problems are increasing as the global aging population grows. Mobile devices have become essential to interacting with friends and society. Because the visually impaired are no exception, it would be useful to determine the functionalities that best support the independence of people with VI. The currently available functionalities and applications were analysed to provide insight about which features the visually impaired value most.

Materials and methods: A Webropol survey with structured and open-ended questions was carried out. The participants $(n=26)$ were asked about their use of mobile applications and opinions regarding the usefulness of certain applications in promoting independent functioning. An instrument was developed for this study based on previous literature, and its quality was assured through an expert panel evaluation and pretesting. The collected data were analysed statistically and by inductive content analysis.

Results: A majority of the participants were active users of mobile devices.

Substantial variation was observed in the evaluations of how useful various applications are to different everyday tasks. The participants suggested numerous improvements, such as additional customisation, to the current mobile devices and applications

- Implications for Rehabilitation:

- People with VI benefit from the use of mobile devices in the same way that the population with normal vision does, and mobile devices and applications can be pivotal to supporting their independence.

- The participants offered innovative ideas and suggestions for how mobile devices and applications could be designed to better meet the needs of the visually impaired.

\section{Word count: 246}

Keywords: mobile application; independence, daily living; visual impairment 


\section{Introduction}

Digitalisation has considerably changed the way of life and activities of daily living (ADL) in Western societies. People now interact with each other and society in novel ways, e.g., service desks have largely been replaced by self-service solutions.

Furthermore, the Internet, mobile phones and social media allow us to interact free from limitations related to time, place, information retrieval and participation (Koiranen,

Räisänen \& Södergård, 2016). Access to information has become increasingly crucial in today's knowledge-intensive society (Hakobyan, Lumsden, O'Sullivan \& Bartlett, 2012), with social and economic participation requiring access to, and use of, wireless technology. However, there are still great differences between populations and groups of people in the use of electronic networks and related services, with certain groups left out of these new kinds of services (Koiranen et al., 2016). Digital exclusion can reduce independence and increase social exclusion (Morris, Sweatman \& Jones, 2017). According to Koiranen et al. (2016), 55-79-year-olds use network services significantly less than younger age groups.

The ease of use, affordability, access to information (Griffin-Shirley, Banda, Ajuwon, Cheon, Lee, Park \& Lyngdoh, 2017), connectivity, size and portability of smartphones make them an important instrument through which people communicate with their social network and participate in digital life. In recent years, the use of mainstream mobile technologies has increased among both the general population as well as people with disabilities (Morris et al., 2017). This pilot study will specifically focus on mobile devices, e.g. smartphones and handheld tablet computers.

Visual impairment (VI) is a general term which describes a wide range of visual functions, from low vision to total blindness (American Foundation for the Blind, 2015). According to the International Statistical Classification of Diseases (ICD-10), the cut-off level for VI defined as blindness is visual acuity (VA) under 0.05 (Snellen decimal) in the better eye. VA under 0.1 is considered severe VI, while VA values under 0.3 and 0.5 constitute moderate and mild VI, respectively (World Health Organization, 2015). It is estimated that globally approximately 1.3 million people live with some form of VI, and that most of those affected are over 50 years of age (World Health Organization, 2018). According to the Finnish register of visual impairment (FRVI), approximately $50000-60000$ Finns are affected by VI, with at least $70 \%$ of them 65 years of age or older (Ojamo, 2017). The leading global causes of vision impairment are uncorrected refractive errors, cataracts, age-related macular degeneration, glaucoma, diabetic retinopathy, corneal opacity and trachoma (World Health Organization, 2018). In Finland, VI is most commonly a result of age-related macular degeneration (Ojamo, 2017). The prevalence of VI markedly increases with age (Flaxman et al., 2017). As such, the prevalence of VI is expected to increase as recent estimates state that $25-30 \%$ of the world's population will be 65 years of age or older by the year 2056 (Markowitz, 2016).

Vision is an essential sense for humans, as the loss of vision affects the performance of almost all ADL. VI reduces the perceived quality of life, affects economic and educational opportunities and increases the risk of death (Bourne et al., 2017) by affecting general lifestyle, personal relationships and professional life (Bhowmick \& Hazarika, 2016). People with VI encounter numerous challenges in 
everyday life, e.g. independent orientation, reading, retrieval of information, running errands, and social interaction (Bhowmick \& Hazarika, 2016; Hakobyan et al., 2012; Mednick, Jaidka, Nesdolc \& Bona, 2017; Riddering, 2016; Rodriguez-Sanchez, Moreno-Alvarez, Borromeo \& Hernandez-Tamames,2014; Siira et al. 2019). Being affected by VI also increases a person's risk of experiencing emotional and/or psychological burden (Mednick et al., 2017).

To actively participate in contemporary society, individuals must be able to retrieve, as well as process, complex information, a skill which is especially challenging for older adults with VI. As such, it is important to understand the barriers that prevent older adults with VI from actively participating in the digital world. For example, older adults with VI face challenges in using touch screen mobile devices, especially with touch screen feedback and icon size (Piper, Brewer \& Cornejo, 2017). Previous research has found that individuals over the age of 65 use mobile devices less often than younger people (Griffin-Shirley et al., 2017). It can be assumed that the issue is no different among people with VI, and it is important to find ways to assist these individuals independently participate in our digitalised, self-service society (Griffin-Shirley et al., 2017).

Science and technology will play a key role in future low vision rehabilitation. However, it should be stated that people affected by VI can only benefit from scientific and technological advances if they possess the skills necessary to use new solutions (Markowitz, 2016). Thus, the VI population should be included in the design process of new technologies to ensure that the solutions can be used by people with VI (Piper et al., 2016). Mobile technologies are rapidly evolving, and new applications appear constantly. Mobile applications, which are colloquially referred to as apps, have also recently become popular among people with VI because of their ease of use (GriffinShirley et al., 2017). Using mobile devices as an assistive tool can help individuals feel less stigmatised or labelled (Hakobyan et al., 2012) and more included in society (Mednick et al., 2017).

Mobile devices can play a pivotal role in improving the quality of life of people with VI (Damaceno, Braga \& Mena-Chalco, 2018). According to Mednick et al. (2017), electronic tablets have immense potential for the VI community. This is because tablets can be used for a variety of everyday tasks, e.g. navigating the internet and using online banking services, and can adapt over time in response to a person's progressive vision loss. Furthermore, people with VI can use tablets to read information and labels that they could otherwise not clearly see, for example, when shopping or cooking. The voice command function of tablets also allows people with VI to stay better connected to the world by providing an alternative for typing. (Mednick et al., 2017).

Independence increases a person's self-worth, confidence and sense of purpose (Mednick et al., 2017). Even though mobile devices can be beneficial for people with VI, they are also associated with certain barriers, e.g. high cost, lack of physical buttons, difficulties with touch screens, limited accessibility tools, issues with speech speed settings, and limited ability to modify text size, colour or contrast (Damaceno et al., 2018).

Only a limited body of research has investigated mobile application use among people with VI. The literature that has focussed on mobile devices use among people with VI has described general smartphone and mobile app use (Griffin-Shirley et al., 2017; Morris et al., 2017), smartphone accessibility (Damaceno et al., 2018; RodriguezSanchez et al., 2014), tablet computers as a tool for rehabilitation (Mednick et al., 2017), general points on assistive technologies (Bhowmick \& Hazarika, 2016; Hakobyan et al., 2012) and how mobile apps are designed (Sanchez Sierra \& Roga de 
Togores, 2012). To the best of our knowledge, no previous research has addressed the extent to which mobile applications support independent living among people with VI. The current paper is a pilot study, and as such, represents the first step to understanding this issue and identifying areas that need to be further researched. The current study is a sound starting point for assessing the feasibility of similar large-scale studies (Junyong, 2017).

This pilot study aimed to describe how the use of mobile apps can support people with VI in performing everyday tasks and living independently. Another aim was to identify which areas of mobile devices and apps need to be developed further to be adequately accessible to people with VI. Hence, the research objective was to provide new knowledge that will be useful for social- and healthcare professionals, low vision rehabilitation centres as well as application developers. Hopefully the results will also be beneficial for people with VI and their relatives. The research was guided by the following questions: 1) What kind of mobile applications do people with VI use in their everyday lives?; 2) How do people with VI evaluate the usefulness of mobile devices and applications in supporting independent living?; and 3) Which aspects of mobile devices and application development do people with VI feel need to be further developed?

\section{Material and Methods}

\section{Survey development and data collection}

The study was carried out in co-operation with the Regional Association of the Visually Impaired in Northern Ostrobothnia (NOVI), Finland. Data were collected by a Webropol survey via the association's mailing list of members with an e-mail address (n $=114$ ) who had given permission that their contact information could be used for research purposes. No currently available instrument was suitable for the study objectives; therefore, a new instrument had to be developed specifically for this study. The new instrument was based on previous literature (Alma, Van Der Mei, MelisDankers, Tilburg, Groothoff \& Suurmeijer, 2010; Bhowmick \& Hazarika, 2016; Damaceno et al., 2018; Griffin-Shirley et al., 2017; Hakobyan et al., 2012; Markowitz, 2016; Mednick et al., 2017; Morris et al., 2017; Piper et al., 2016; Plaza, Martin, Martin \& Medrano, 2011; Riddering, 2016; Rodriguez-Sanchez et al., 2014; Sanchez Sierra \& Roga de Togores, 2012) and knowledge, with quality assured through evaluation by an expert panel and pre-testing.

The first version of the instrument (46 questions and 7 items) was evaluated by a panel of experts which included professionals from the fields of ophthalmology and low vision rehabilitation (an ophthalmologist, low vision rehabilitation counsellors, experts on advocacy work, an ICT trainer, and the executive director of NOVI), as well as people of various ages living with VI. There were 14 people in the panel, but as low vision rehabilitation counsellors $(n=5)$ answered as a group, each question and item received 10 distinct evaluations. The panel evaluated the relevance of questions and items based on a scale ranging from "very relevant" to "not relevant at all" and gave feedback on how the questionnaire could be improved. The expert panel also evaluated the comprehensibility and unambiguousness of the questionnaire. The content validity index (CVI) was calculated based on the expert panel's evaluations of every question. Based on the CVI, some of the questions $(n=8)$ and items $(n=2)$ were left out of the final 
questionnaire. Several improvements were also made, more specifically, questions and items were rephrased so that they would be easier to understand while similar questions and items were combined into one question or item. After the expert panel evaluation, as well as the subsequent improvements, the questionnaire was pretested on a group of members from the Regional Association of the VI in Lapland in March 2019. The pretesting results demonstrated that the survey was functional, and no further changes were made.

The survey was carried out by the NOVI ICT trainer via the association's mailing list. Prior to the survey, members of the association were informed about the survey through a newsletter, and technologically active members were encouraged to participate. They were also reminded about the survey three times via e-mail and at the association's events. The survey was carried out between $7^{\text {th }}$ May and $19^{\text {th }}$ June 2019. The questionnaire consisted of questions $(n=8)$ and items $(n=2)$ about background characteristics, questions $(n=14)$ and items $(n=5)$ about the participants' mobile device backgrounds and user experiences, items $(n=5)$ concerning how useful different functions in mobile devices and mobile applications are in relation to different ADL, and open-ended questions $(n=4)$ regarding how participants feel that mobile devices and applications could be developed further. ADL functions were categorised as follows: using a mobile device; information retrieval and reading; independent orientation; running errands; and leisure time. Participants scored the items on a five-point Likert scale ranging from "strongly agree" to "strongly disagree". In addition, each item included additional space so that participants could elaborate on their answer. The sample size was not calculated in this study because a pilot study is not undertaken for the purpose of hypothesis testing (Junyong, 2017).

The research was conducted according to good scientific practice and followed the ethical principles of the Helsinki Declaration (TENK, 2012). Respondents' personal data were handled confidentially and anonymously, i.e. the researchers did not have the respondents' names or contact information at any point of the research. The respondents were informed about the research process so that they could freely decide whether to participate or not. Moreover, all of the participants were told that they could contact the researchers to ask questions about the survey (Polit \& Beck, 2017). The participants had given permission that their contact information could be used for research purposes when joining the mailing list, so a new research permit was not needed (TENK, 2012).

The participants were recruited via the NOVI mailing list as it was considered a decent way to reach members with positive attitudes towards technology. The informational letter encouraged active users of mobile devices to participate.

\section{Participants}

The participants were members of the NOVI mailing list. A total of 26 participants completed the survey and answered the questionnaire. They represent $23 \%$ of the members to whom the survey was sent to. One of the participants gave answers with the help of a personal assistant as he/she was not able to answer the questionnaire independently. The background characteristics of the sample are provided in table 1. Most $(73 \%)$ of the participants were over 46 years old, with one-third (31\%) between the ages of 63-79. A majority of the participants $(n=18,69 \%)$ were male, while 21 $(81 \%)$ were living in urban areas, $18(69 \%)$ reported living with someone and $15(58 \%)$ had completed education at a university or university of applied sciences. In terms of employment status, 10 (39\%) were employed, eight (31\%) were retired because of 
health issues, six (23\%) were retired based on age or working years, one (4\%) was working part-time and one (4\%) was unemployed. A significant share of the participants evaluated their state of health (46\%) and functional ability $(42 \%)$ as good. The selfreported diagnoses for VI included hereditary retinal diseases, other retinal diseases, congenital reasons or syndromes, glaucoma, optic neuropathy, and trauma, along with other less commonly reported factors.

\section{Data analysis}

Descriptive statistics were calculated using SPSS Statistics 24 (IBM, Armonk, NY) to summarise participants' background characteristics, their use of mobile devices and applications, as well as their evaluations of the usefulness of different mobile applications and functions in relation to various ADL functions. The qualitative data from open-ended questions were analysed using inductive content analysis (Elo \& Kyngäs, 2008). Briefly, the researchers specified certain codes that were relevant to the studied phenomenon. Whenever part of an answer - whether a sentence, phrase or term - reflected one of these codes, the researchers marked the content and placed it in the appropriate category. Insights from the qualitative data are presented as the number of respondents who provided content that matched with one of the codes.

\section{Results}

\section{The use of mobile devices and applications}

Table 2 provides information about how the participants use their mobile devices and apps in everyday life.

Most of the participants (42\%) reported using either a smartphone or both a smartphone and tablet in everyday life. Participants who have both mobile devices reported preferring to use a smartphone (69\%). The majority of the respondents $(58 \%)$ reported that the mobile device was very important to them. Typically, the respondents had either purchased their device with the help of a family member or a friend (39\%) or had not needed assistance (39\%). The participants predominantly reported relying on either family and friends (46\%) or NOVI and its ICT services (31\%) to resolve problems with their mobile devices. Some participants also reported turning to their social network or other mobile device users for help. The majority of the respondents were interested $(50 \%)$ or very interested $(39 \%)$ in using mobile devices or mobile technology and had no (39\%) or little (35\%) preconceptions about using mobile devices or technology. Half of the participants felt that their preconceptions had eased after they started using their mobile devices, while the other half reported that their preconceptions had either been neutral or not changed as a result of mobile device use.

The mobile devices were used for telephone calls, SMS messages, instant messages, storing photos, accessing social media, entertainment, information retrieval, running errands, independent orientation and other, i.e. audiobooks, diary, e-mail, text reading, weather, stock market prices and betting. The respondents most commonly used the $\mathrm{iOS} \circledast$ operating system (50\% of smart phones, $39 \%$ of tablets). The majority of respondents $(62 \%)$ had owned a mobile device for over five years and were using mobile devices one to three hours daily (46\%). Most of the respondents (46\%) reported 
having downloaded more than 15 applications on their devices and using between six and ten apps on a daily basis (46\%). The respondents reported using mobile devices at home, at school or work, during hobbies, for independent orientation, and when running errands, with three of the respondents reporting that they used the devices in other locations, e.g. in the car, when travelling and everywhere all the time. Some of the participants reported that mobile applications had reduced their use of "on the spot" services, e.g. bank services, public services and/or groceries. The participants reported getting information about new applications mainly from family or friends. Mobile app stores, advertisements, the internet and media were also mentioned as sources of information. There was large variation in the amount of time (ranging from none to very much) that respondents reported spending on their mobile devices for different tasks, e.g. communication, information retrieval or reading, independent orientation, running errands and entertainment (Table 3).

\section{The usefulness of mobile applications and functions}

Table 3 provides information on how participants evaluated the usefulness of different mobile applications and functions in relation to different ADL. Several respondents were not able to evaluate how useful different applications are for using the mobile device, information retrieval and reading, supporting independent orientation, running errands or leisure time.

\section{Mobile applications and functions related to the use of a mobile device}

The majority of the respondents felt that the virtual assistant $\operatorname{Siri}{ }^{\circledR}$ in iOS $®$ is a useful function for using a mobile device, and reported dictation apps, the zooming function and screen reading apps to be useful as well. In contrast, most of the respondents reported that the reverse colours function, augmented screen, simplified screen and braille apps were not useful. The augmented text function split opinions. Screen dimming and Seeing Artificial Intelligence (AI) were mentioned as very useful functions or applications.

\section{Mobile applications and functions related to information retrieval and reading}

Most of the respondents evaluated web browsers, audiobook apps and the Luetus ${ }^{\circledR}$ app to be useful for information retrieval and reading. In contrast, the respondents felt that E-book apps, text reading apps, visual identification apps, social media and the Be My Eyes ${ }^{\circledR}$ app were not useful for information retrieval and reading. Other journal apps that had not been specifically designed for people with VI split opinions. iXpand®, virtual assistant Siri ${ }^{\circledR}$, Microsoft Word ${ }^{\circledR}$ document and word processing software and OneDrive ${ }^{\circledR}$ were mentioned as useful apps (Table 3).

\section{Mobile applications and functions related to independent orientation}

Most of the participants, all of whom were affected by VI, reported that navigation apps which had not been specifically designed for people with VI, along with public transport or taxi apps, were useful for supporting independent orientation. Navigation apps designed specifically for people with VI, city guide apps, visual identification apps 
and the Be My Eyes® app were evaluated as not useful. The virtual assistant Siri® was mentioned as a moderately useful function for independent orientation (Table 3).

\section{Mobile applications and functions related to running errands}

The majority of the respondents felt that navigation apps which had not been specifically designed for people with VI and service apps (e.g. mobile bank, appointments, public transport, etc.) are useful for running errands. In contrast, they reported that navigation apps designed specifically for people with VI, city guide apps, barcode and QR code reader, text reading apps, visual identification apps, social media and the Be My Eyes ${ }^{\circledR}$ app were not useful for running errands. E-mail was mentioned as a useful app (Table 3).

\section{Mobile applications and functions related to leisure time}

Most of the participants felt that navigation apps which had not been specifically designed for people with VI, the Luetus ${ }^{\circledR}$ app, journal apps which had not been specifically designed for people with VI, service apps (e.g. mobile bank, appointments, public transportation, etc.), social media, e-mail and entertainment apps which had not been specifically designed for people with VI were useful for leisure purposes. In contrast, the participants reported that navigation apps which had been designed for people with VI, city guide apps, text reading apps, visual identification apps, entertainment apps that had been designed for people with VI and game apps were not useful for leisure purposes. Pratsam Reader ${ }^{\circledR}$ was mentioned as a useful app (Table 3).

\section{Needs for further mobile device and application development}

Based on their experiences, the participants would like to be able to independently use mobile devices for online banking, independent orientation, listening to e-books, gambling and for better image and text recognition. Several respondents reported that they would like to be able to order transportation services via an application, with one participant stating that the process would be less complicated when there is no contact with people. Another respondent stated that they think that monitoring blood sugar levels would be easier via a sensor and application. Moreover, one of the participants commented that they are unable to use mobile devices because of a lack of sight.

The respondents reported that they would like the mobile devices to have larger screens and longer-lasting batteries. Furthermore, they felt that touch screen sensibility could be improved, and called for better image recognition algorithms, improvements to VoiceOver ${ }^{\circledR}$ interpretation and button names - so that VoiceOver ${ }^{\circledR}$ can read them properly - and extensive improvements to Finnish text reading. The participants also reported that more applications, especially navigation apps, should be compatible with voice commands. The customisation of settings, e.g. contrast, text size and colours, was mentioned, while some of the participants felt that the devices should have more actual buttons and provide better connectivity between mobile devices and assistive tools for people with VI. Some of the participants felt that every application should include an enlarging feature. Some of the participants mentioned that they still need help and guidance to use mobile devices and apps, while one respondent stated that using a computer remains easier than using mobile devices. 


\section{Discussion}

This pilot study provides interesting insight into how people with VI use mobile devices in their everyday life, as well as identifies how mobile devices could be improved to further assist the independence of people with VI. It is now well recognised that the information communications technology field is constantly changing, and that these technologies impact myriad aspects of everyday life. This is also the case for people with VI, who are learning to take advantage of mobile devices and applications to live independently. However, these technologies and solutions also have some pitfalls. This study aimed to provide an initial description of how people with VI use mobile devices as assistive technologies in everyday life.

The participants were mainly middle-aged and older adults with VI. They were able to complete an internet-based survey independently with their devices, which is a result per se and demonstrates their technological competence. Based on the results, mobile devices were very important to the respondents, most of whom reported a general interest in mobile devices, applications and mobile technology. As the participants did not have strong preconceptions about mobile technology, it is not surprising that half of the participants felt that their preconceptions had not changed after starting to use mobile devices. The respondents used mobile devices for the same purposes as people with normal vision, and are active users of mobile devices and applications even though it could have been assumed that they do not often use devices based on their age (Griffin-Shirley et al., 2017). The iOS® operating system is more accessible (via built-in functions and applications) to people with VI than other operating systems (The Apple Inc., 2019) and, for this reason, it was not surprising that iOS $®$ was the most common operating system among the participants. The participants reported using smartphones more than tablets, a finding that is perhaps explained by the better portability of smartphones. The results of this pilot study demonstrated that people with VI widely consider mobile devices as a tool to support their independence in everyday life. These results support previous findings that mobile devices are rather easy to use, affordable, accessible and do not stigmatise users the way that other assistive tools and devices may do (Griffin-Shirley et al., 2017; Hakobyan e al., 2012).

The respondents' evaluations of how useful certain applications are in everyday life varied considerably. A surprising result was that some respondents could not judge the usefulness of mobile applications and functions to daily activities. This may be explained by the respondents being unfamiliar with the applications and/or functions. Also, some of the participants may have been confused by the vocabulary used to discuss the subject. The respondents reported a general need for learning how to use mobile devices and applications, and certain low vision rehabilitation centres may face challenges in providing this type of service. These findings suggest that professionals in the low vision rehabilitation field will need to be increasingly prepared to help patients use their mobile devices and find apps that can serve as visual aids.

Mobile devices are becoming increasingly accessible to people with VI, and are crucial in supporting these people with everyday life and participations in different sectors of society (Markowich, 2016; Mednick et al., 2017). Managing daily tasks independently has lots of benefits, but can also have drawbacks. For example, a person who is able to access diverse services without leaving home may, knowingly or unknowingly, narrow their circle of friends, which can eventually decrease functional ability (Siira, 2019).

The respondents also identified many areas of mobile devices and applications that need improvement in order to make them easier to use. For example, the people with VI who participated in this study felt that text reading apps need further 
development to become truly useful for the visually impaired. The respondents also thought that navigation apps that had been specifically designed for people with VI are not as useful as general navigation apps, which was rather unexpected. To be useful to people with VI, navigation apps require excellent voice commands that will allow people with VI to navigate independently. A large share of the respondents reported that they would like to run their errands through applications, but this is not yet fully possible. In addition, the respondents called for more customisable options and better compatibility between assistive tools and applications. Today's world is becoming increasingly visual, and the visually impaired want to be part of it as well. This might explain the respondents' demands for better visual identification apps. The results agree with the findings of previous studies both in terms of difficulties faced by people with VI when using mobile devices (Damaceno et al., 2018) and the tasks that people with VI need mobile devices and applications for (Bhowmick \& Hazarika, 2016; Hakobyan et al., 2012; Mednick et al, 2017; Riddering, 2016; Rodriguez-Sanchez et al., 2014; Siira et al., 2019).

Application developers should also take into account what features the visually impaired will need when creating new functionalities (Piper et al., 2017) and ensure accessibility and compatibility between different software and applications. This is supported by the current findings, as Finnish people with VI, even the senior citizens, actively use mobile devices and share a positive attitude towards digitalisation. Moreover, the study participants were open-minded towards technology and had adopted mainstream applications rather easily. For this reason, a design-for-all approach is advantageous, as applications that can be used by people with VI represent applications that are functional for everyone in society.

The survey was carried out as an internet survey based on NOVI experiences of Webropol surveys with their members. The instrument development process was systematic, based on a sufficient number of previous studies, and resulted in an instrument that was determined to be relevant for the studied phenomenon of mobile device and application used among the visually impaired. The expert panel included professionals from the fields of ophthalmology and low vision rehabilitation, and provided valuable feedback that was implemented to improve the questionnaire and the instrument's internal and external validity. The expert panel was instructed to calculate a CVI (content validity index) to increase the validity of the instrument. The expert panel also evaluated the questionnaire's comprehensibility and unambiguousness, which can be expected to increase instrument reliability. Pretesting on a group that is similar to the study population was performed to further improve instrument reliability (Graneheim \& Lundman, 2003; Metsämuuronen, 2006, Polit \& Beck, 2017).

The response rate, $23 \%$, was rather low. However, those who responded succeeded in independently completing the survey, even if VI might have caused some difficulties. The respondents also provided very informative answers to the open-ended questions. It should also be noted that the mailing list includes people who do not use mobile devices, children, along with normal-sighted relatives of someone with VI, so the researchers did not expect everyone in the mailing list to participate in the study. NOVI does not have any systematic data about how many of their members actively use mobile devices, but the association estimates this number to be rather small based on the age distribution of the members (mean age is about 70 years). Furthermore, the association assumes that most of the members who actively use mobile devices and who have positive attitudes towards technology are on the mailing list. It is encouraging that a Webropol survey proved to be a successful data collection method among people with VI, and that they were able to fill in the questionnaire independently and provide 
answers to open-ended questions. Therefore, the study objective, i.e. exploring the unknown field of the digital lives of the visually impaired, was fulfilled.

The trustworthiness of any research is evaluated by its credibility, transferability, dependability and confirmability (Lincoln \& Guba, 1985). The credibility was assured by a successful instrument development process, which provided an instrument that could reliably gather participant evaluations about the research subject. A transparent and comprehensible description of the research process has ensured transferability. To ensure dependability, the researcher analysed the collected data objectively and drew parallels to what has been reported in previous research. However, one weakness of the research was confirmability, which was rather low due to the small respondent group (Kyngäs, Mikkonen, Kääriäinen, 2020). In this study, both quantitative and qualitative data were collected, after which they were combined to provide reliable information (Metsämuuronen, 2006). The inductive content analysis approach was easy to carry out objectively because the data from open-ended questions were mainly clearly expressed and logical to categorise.

Future research should attempt to gain deeper insight about which functionalities people with VI most value in mobile devices and applications. Qualitative research employing interviews could provide a sufficient depth of data for investigating this topic. Additional research could build on the current study by expanding the target population through co-operation with a nationwide umbrella organisation, further developing the instrument used in the present research, and including a follow-up time point to investigate how functionalities in mobile devices and applications have changed over time.

The information this study has provided on people with VI, who already quite actively use mobile devices, could be pivotal to both understanding how people with VI perform everyday activities and identifying how mobile devices can support the independence of the visually impaired. The number of elderly citizens is increasing, which will cause various demographic challenges, some of which can be eased by innovative technological solutions. There are still lots of people with VI, especially those over 65 years of age, who are not very familiar with ICT technology (GriffinShirley et al., 2017). Today's elderly people have lived with technology for just a small part of their lives, so it may be too much to expect that they will all become proficient at using emerging technologies. Nevertheless, the next generation is already using mobile devices and technologies in their everyday life, so it can be assumed that older age groups will increasingly benefit from mobile devices in the future. The presented results thus provide useful information for how mobile devices and applications can be adapted for the visually impaired. This insight has societal relevance as the elderly will soon make up 30\% of the population and the incidence of VI is constantly increasing. Mobile applications developers could use the findings of this study to transform mobile devices into assistive tools that support the independence of people with VI and make them feel included in society.This pilot study has laid the framework for larger-scale studies, which will yield more generalisable results and accurately describe what types of functionalities people with VI need from mobile devices to independently perform everyday tasks.

\section{Conclusions}

The present research demonstrated that many individuals with VI are technologically proficient and actively use mobile devices in their everyday lives. Furthermore, the 
visually impaired and individuals with normal vision generally use mobile devices for similar everyday purposes. However, most of the individuals with VI who are active users have completed higher education and/or are younger than an average Finnish subject with low vision or blindness. The participants had varying opinions regarding the usefulness of mobile devices and applications. A large share of the participants was willing to use mobile devices and applications to support independent living; however, the respondents also offered numerous suggestions for how the devices and applications could better serve the visually impaired. It should be stated that the respondents demonstrated extensive understanding of mobile technologies and expressed innovative ideas and concrete propositions for mobile application developers to consider.

\section{Acknowledgments}

The authors would like to acknowledge all of the professionals who participated in this research for their valuable efforts in the expert panel evaluation of the instrument. The authors would also like to thank the NOVI's ICT trainer for the technical execution of the survey. Sincere gratitude goes to the all the participants for taking their time to complete the questionnaire.

\section{Declaration of interest statement}

The authors have no competing interests to declare.

\section{References}

Alma MA, Van Der Mei SF, Melis-Dankers BJM, et al. Participation of the elderly after vision loss. Disabil Rehabil. 2011;33(1):63-72.

American Foundation for the Blind. 2015. Visual Impairment [Internet]. American Foundation for the Blind; [cited 2019]. Available from: https://www.afb.org/blindness-and-low-vision/eye-conditions/low-vision-andlegal-blindness-terms-and-descriptions.

Apple Inc. 2019. Accessibility [Internet]. Apple Inc.; [cited 2019] Available from: https://www.apple.com/accessibility/iphone/vision/.

Bhowmick A, Hazarika SM. An insight into assistive technology for the visually impaired and blind people: state-of-art and future trends. J Multimodal User In. 2016;11:149-172.

Bourne RRA, Flaxman SR, Braithwaite T, et al. Magnitude, temporal trends, and projections of the global prevalence of blindness and distance and near vision impairment: a systematic review and meta-analysis. Lancet Glob Health. 2017;5:888-897. 
Damaceno RJP, Braga JC, Mena-Chalco JP. Mobile device accessibility for the visually impaired: problems mapping and recommendations. Univ Access Inf Soc. 2018; $17: 421-435$.

Elo S, Kyngäs H. The qualitative content analysis process. J Adv Nurs. 2008;62(1):107-115.

Flaxman SR, Bourne RRA, Resnikoff S, et al. Global causes of blindness and distance vision impairment 1990-2020: a systematic review and meta-analysis. Lancet Glob Health. 2017;5:1221-1234.

Graneheim UH, Lundman B. Qualitative content analysis in nursing research: concepts, procedures and measures to achieve trustworthiness. Nurse Educ Today. 2003;24:105-112.

Griffin-Shirley N, Banda DR, Ahuwon PM, et al. A survey on the use of mobile applications for people who are visually impaired. J Vis Impair Blind. 2017;111(4):307-323.

Hakobyan L, Lumsden J, O'Sullivan D, et al. Mobile assistive technologies for the visually impaired. Surv Ophthalmol. 2012;58:513-528.

Junyong I. Introduction of a pilot study. Korean J Anesthesiol. 2017;70(6):601-605.

Koiranen I, Räsänen P, Södergård C. Mitä digitalisaatio on tarkoittanut kansalaisen näkökulmasta? [What has digitalization meant from a citizen's point of view?]. Talous ja Yhteiskunta 2016;3:24-29.

Kyngäs H, Mikkonen K, Kääriäinen M. The application of content analysis in nursing science research. New York (NY): Springer International Publishing; 2020.

Lincoln YS, Guba EG. Naturalistic inquiry. Newbury Park (CA): Sage Publications; 1985. Available from: http://www.qualres.org/HomeLinc-3684.html.

Markowitz SN. State-of-the-art: low vision rehabilitation. Can J Ophthalmol. 2016;51(2):59-66.

Mednick Z, Jaidka A, Nesdole R, et al. Assessing the iPad as a tool for low-vision rehabilitation. Can J Ophthalmol. 2017;52(1):13-19.

Metsämuuronen J. Tutkimuksen tekemisen perusteet ihmistieteissä [The research basics in human sciences], 2nd ed. Jyväskylä: Gummerus; 2006.

Morris JT, Sweatman M, Jones ML. Smartphone use and activities by people with disabilities: user survey 2016. Journal of Technology and Persons with Disabilities. 2017;50-67. 
Ojamo M. Annual statistics 2017. The Finnish Register of Visual Impairment. Helsinki: National Institute for Health and Welfare (THL); 2017.

Piper AM, Brewer R, Cornejo R. Technology learning and use among older adults with late-life vision impairments. Univ Access Inf Soc. 2017;16:699-711.

Plaza I, Martin L, Martin S, et al. Mobile applications in aging society: status and trends. J Syst Softw. 2011;84:1977-1988.

Polit DE, Beck CT. Nursing research - generating and assessing evidence for nursing practice, 10th ed. China. Alphen aan den Rijn: Wolters Kluwer; 2017.

Riddering AT. Visual impairment and factors associated with difficulties with daily tasks [dissertation]. Kalamazoo (MI): Western Michigan University; 2016.

Rodriguez-Sanchez MC, Moreno-Alvarez MA, Martin E, et al. Accessible smartphones for blind users: a case study for a wayfinding system. Expert Sys Appl. 2014;41:7210-7222.

Sanchez Sierra J, Roga de Togores J. Designing mobile apps for visually impaired and blind users. Using touch screen based mobile devices: iPhone/iPad. ACHI 2012: The Fifth International Conference on Advances in Computer-Human Interactions; 2012 Jan 30 - Feb 4; Valencia, Spain.

Siira H. Aistivammaystävällisyys näkökulma esteettömyyteen [Sensory-Friendly Perspective on Accessibility]. ProTerveys 2019;2:26.

Siira HJ, Falck AAK, Kyngäs HA. Health-related quality of life and related factors among elderly people with visual impairments. Br J Vis Impair. 2019;27:1-11.

Varantola K, Launis V, Helin M, et al. (Eds.). Responsible conduct of research and procedures for handling allegations of misconduct in Finland. Guidelines of the Finnish Advisory Board on Research Integrity 2012. Helsinki: Finnish Advisory Board on Research Integrity; 2012.

World Health Organization. 2018. Blindness and Vision Impairment [Internet]. World Health Organization; [Cited 2019]. Available from https://www.who.int/newsroom/fact-sheets/detail/blindness-and-visual-impairment.

World Health Organization. 2015. ICD-10: International Statistical Classification of Diseases and Related Health Problems. [Internet]. World Health Organization; [Cited 2019]. Available from: https://icd.who.int/browse10/2015/en. 


\section{Appendices}

Table 1 . The background characteristics of study participants $(n=26)$.

\begin{tabular}{|c|c|c|}
\hline Background variable & $\mathrm{n}$ & $\%$ \\
\hline Age (years) & 26 & \\
\hline$<18$ & 0 & 0 \\
\hline $18-29$ & 1 & 3,8 \\
\hline $30-45$ & 6 & 23,1 \\
\hline $46-62$ & 11 & 42,3 \\
\hline $63-79$ & 8 & 30,8 \\
\hline$>80$ & 0 & 0 \\
\hline Gender & 26 & \\
\hline Female & 8 & 30,8 \\
\hline Male & 18 & 69,2 \\
\hline Area of living & 25 & \\
\hline Urban & 21 & 80,8 \\
\hline Rural & 4 & 15,4 \\
\hline Education & 26 & \\
\hline Grammar school & 1 & 3,8 \\
\hline Primary school & 0 & 0 \\
\hline High school & 0 & 0 \\
\hline Vocational school or similar & 10 & 38,5 \\
\hline University/ Uni. of Applied Sciences & 15 & 57,7 \\
\hline Living alone & 25 & \\
\hline Yes & 7 & 26,9 \\
\hline No & 18 & 69,2 \\
\hline Employment status & 26 & \\
\hline Employed & 10 & 38,5 \\
\hline Working part-time & 1 & 3,8 \\
\hline Unemployed & 1 & 3,8 \\
\hline Retired by age or working years & 6 & 23,1 \\
\hline Retired by other reason & 8 & 30,8 \\
\hline State of health & 26 & \\
\hline Poor & 0 & 0 \\
\hline Bad & 3 & 11,5 \\
\hline Neutral & 6 & 23,1 \\
\hline Good & 12 & 46,2 \\
\hline Excellent & 5 & 19,2 \\
\hline Functional ability & 24 & \\
\hline Poor & 0 & 0 \\
\hline Bad & 2 & 7,7 \\
\hline Neutral & 7 & 26,9 \\
\hline Good & 11 & 42,3 \\
\hline Excellent & 4 & 15,4 \\
\hline
\end{tabular}


Table 2. Study participant use and experiences of mobile devices $(n=26)$.

\begin{tabular}{|c|c|c|}
\hline Mobile device use and experiences & $\mathrm{n}$ & $\%$ \\
\hline Mobile device & 25 & \\
\hline Smartphone & 11 & 42,3 \\
\hline Tablet computer & 2 & 7,7 \\
\hline Both & 11 & 42,3 \\
\hline No mobile device & 1 & 3,8 \\
\hline Preferred device & 25 & \\
\hline Smartphone & 18 & 69,2 \\
\hline Tablet computer & 2 & 7,7 \\
\hline Both & 4 & 15,4 \\
\hline No mobile device & 1 & 3,8 \\
\hline Importance of mobile device & 24 & \\
\hline Not important at all & 1 & 3,8 \\
\hline Not so important & 1 & 3,8 \\
\hline Neutral & 2 & 7,7 \\
\hline Important & 4 & 15,4 \\
\hline Very important & 15 & 57,7 \\
\hline Can't say & 1 & 3,8 \\
\hline Received help for purchase of a mobile device from & 26 & \\
\hline Salesman & 0 & 0 \\
\hline Family/friend & 10 & 38,5 \\
\hline Personal assistant & 1 & 3,8 \\
\hline Regional Association of the Visually Impaired (NOVI) & 7 & 26,9 \\
\hline Needed help, but did not receive it & 2 & 7,7 \\
\hline Did not need help & 10 & 38,5 \\
\hline Other & 1 & 3,8 \\
\hline $\begin{array}{l}\text { Help for start of use and/or problems using a mobile device } \\
\text { was received from }\end{array}$ & 25 & \\
\hline Salesman & 0 & 0 \\
\hline Family/friend & 12 & 46,2 \\
\hline Personal assistant & 4 & 15,4 \\
\hline Regional association of the visually impaired (NOVI) & 8 & 30,8 \\
\hline Needed help, but did not receive it & 1 & 3,8 \\
\hline Did not need help & 6 & 23,1 \\
\hline Other & 2 & 7,7 \\
\hline Interest for using mobile devices or mobile technology & 26 & \\
\hline Not interested at all & 0 & 0 \\
\hline Not so interested & 2 & 7,7 \\
\hline Neutral & 1 & 3,8 \\
\hline Intereseted & 13 & 50 \\
\hline Very interested & 10 & 38,5 \\
\hline Can't say & 0 & 0 \\
\hline $\begin{array}{l}\text { Preconceptions of mobile devices or mobile technology } \\
\text { before use }\end{array}$ & 26 & \\
\hline No preconceptions at all & 10 & 38,5 \\
\hline
\end{tabular}


$\begin{array}{lll}\text { Not strong preconceptions } & 9 & 34,6\end{array}$

$\begin{array}{lll}\text { Neutral } & 2 & 7,7\end{array}$

$\begin{array}{lll}\text { Some preconceptions } & 3 & 11,5\end{array}$

$\begin{array}{lll}\text { Very strong preconceptions } & 2 & 7,7\end{array}$

Can't say

How did preconceptions of mobile devices or mobile 24

technology change after use

No change at all

Not much change

Neutral

Preconceptions changed

Preconceptions strongly changed

Can't say

Mobile devices are used for

Calls

SMS messages

84,6

Instant message

57,7

Storing photos

Accessing social media

73,1

Entertainment

61,5

Information retrieval

69,2

Running errands

76,9

Independent orientation

73,1

Other

46,2

Smartphone operating system

30,8

iOS

Android

38,5

Does not use

Does not know

Tablet operating system

iOS

Android

Does not use

Does not know

Years of having a mobile device

Less than 1 year

1-3 years

3-5 years

More than 5 years

Daily use of a mobile device (in hours)

Less than 1 hour

1-3 hours

3-5 hours

More than 5 hours

Number of loaded mobile applications on a device 
More than 15 pcs

Can't say

Number of mobile applications used daily

None

$1-5 \mathrm{pcs}$

6-10 pcs

1246,2

More than 10 pcs

$2 \quad 7,7$

Can't say

Where the mobile device is used

At home

At school or work

At hobbies

$10 \quad 38,5$

For independent orientation

$14 \quad 53,8$

For running errands

$15 \quad 57,7$

Other

$3 \quad 11,5$

Information about new applications acquired from

Family/friend

Social media

Internet forums for visually impaired 
Table 3 Study participant evaluations of the use and usefulness of mobile devices and applications $(\mathrm{n}=26)$.

\begin{tabular}{|c|c|c|c|c|c|c|c|}
\hline Time of use of a mobile device for & $\mathrm{n}$ & $\begin{array}{r}\text { Not at all, } \mathrm{n} \\
(\%)\end{array}$ & $\begin{array}{r}\text { Not much, } \mathrm{n} \\
(\%)\end{array}$ & Some, n (\%) & Much, n (\%) & $\begin{array}{r}\text { Very much, } \mathrm{n} \\
(\%)\end{array}$ & $\begin{array}{r}\text { Can't say, } \mathrm{n} \\
(\%)\end{array}$ \\
\hline Communication & 25 & $2(7,7)$ & $2(7,7)$ & $7(26,9)$ & $3(11,5)$ & $10(38,5)$ & $1(3,8)$ \\
\hline Information retrieval or reading & 24 & $2(7,7)$ & $5(19,2)$ & $5(19,2)$ & $6(23,1)$ & $5(19,2)$ & $1(3,8)$ \\
\hline Independent orientation & 23 & $11(42,3)$ & $3(11,5)$ & $6(23,1)$ & $1(3,8)$ & $1(3,8)$ & $1(3,8)$ \\
\hline Running errands & 24 & $5(19,2)$ & $3(11,5)$ & $6(23,1)$ & $6(23,1)$ & $3(11,5)$ & $1(3,8)$ \\
\hline Entertainment & 24 & $4(15,4)$ & $6(23,1)$ & $2(7,7)$ & $4(15,4)$ & $7(26,9)$ & $1(3,8)$ \\
\hline $\begin{array}{l}\text { The usefulness of mobile applications in } \\
\text { relation to different ADL }\end{array}$ & $\mathrm{n}$ & $\begin{array}{r}\text { Not useful at } \\
\text { all, } \mathrm{n}(\%) \\
\end{array}$ & $\begin{array}{r}\text { Not so useful, } \\
\mathrm{n}(\%) \\
\end{array}$ & $\begin{array}{r}\text { Moderately } \\
\text { useful, n }(\%) \\
\end{array}$ & Useful, n (\%) & $\begin{array}{r}\text { Very useful, } \mathrm{n} \\
(\%) \\
\end{array}$ & $\begin{array}{r}\text { Can't say, } \mathrm{n} \\
(\%) \\
\end{array}$ \\
\hline \multicolumn{8}{|l|}{ Using a mobile device } \\
\hline Virtual assistant Siri® (iOS) & 26 & $3(11,5)$ & $2(7,7)$ & $2(7,7)$ & $3(11,5)$ & $8(30,8)$ & $8(30,8)$ \\
\hline Dictation apps & 25 & $4(15,4)$ & $2(7,7)$ & $4(15,4)$ & $2(7,7)$ & $5(19,2)$ & $8(30,8)$ \\
\hline Reverse colours function & 26 & $12(46,2)$ & $1(3,8)$ & $3(11,5)$ & 0 & $4(15,4)$ & $6(23,1)$ \\
\hline Augmented text function & 26 & $9(34,6)$ & $1(3,8)$ & $1(3,8)$ & $5(19,2)$ & $9(34,6)$ & $1(3,8)$ \\
\hline Augmented screen & 24 & $10(38,5)$ & $1(3,8)$ & $4(15,4)$ & 0 & $5(19,2)$ & $4(15,4)$ \\
\hline Simplified screen & 26 & $14(53,8)$ & 0 & $2(7,7)$ & $2(7,7)$ & $4(15,4)$ & $4(15,4)$ \\
\hline Zooming function & 25 & $8(30,8)$ & $2(7,7)$ & $1(3,8)$ & $1(3,8)$ & $10(38,5)$ & $3(11,5)$ \\
\hline Screen reading apps & 26 & $6(23,1)$ & 0 & 0 & $2(7,7)$ & $8(30,8)$ & $10(38,5)$ \\
\hline Braille apps & 26 & $15(57,7)$ & 0 & $1(3,8)$ & 0 & 0 & $10(38,5)$ \\
\hline Other & 8 & $1(3,8)$ & 0 & 0 & 0 & $2(7,7)$ & $5(19,2)$ \\
\hline \multicolumn{8}{|l|}{ Information retrieval and reading } \\
\hline Web browsers & 25 & $3(11,5)$ & 0 & $2(7,7)$ & $6(23,1)$ & $14(53,8)$ & $\overline{0}$ \\
\hline Audiobook apps & 25 & $4(15,4)$ & $1(3,8)$ & 0 & $2(7,7)$ & $14(53,8)$ & $4(15,4)$ \\
\hline E-book apps & 25 & $9(34,6)$ & $1(3,8)$ & $3(11,5)$ & $1(3,8)$ & $4(15,4)$ & $7(26,9)$ \\
\hline $\begin{array}{l}\text { Luetus }{ }^{\circledR} \text { (journal app designed for people } \\
\text { with VI) }\end{array}$ & 26 & $4(15,4)$ & $1(3,8)$ & $4(15,4)$ & $2(7,7)$ & $9(34,6)$ & $6(23,1)$ \\
\hline
\end{tabular}


Other journal apps

Text reading apps

$26 \quad 5(19,2) \quad 5(19,2)$

Visual identification apps

$7(26,9)$

$5(19,2)$

$2(7,7)$

$2(7,7)$

$5(19,2)$

$7(26,9)$

Social media

Be My Eyes® app

$\begin{array}{ll}26 & 9(34,6) \\ 26 & 8(30,8)\end{array}$

$1(3,8)$

$1(3,8)$

$2(7,7)$

$3(11,5)$

$8(30,8)$

$9(34,6)$

$3(11,5)$

$1(3,8)$

$1(3,8)$

$11(42,3)$

26

$1(3,8)$

$2(7,7)$

$6(23,1)$

$4(15,4)$

$7(26,9)$

$1(3,8)$

Other

7

$1(3,8)$

$2(7,7)$

$1(3,8)$

$1(3,8)$

$2(46,2)$

Independent orientation

Navigation apps designed for people with

VI (e.g. BlindSquare®)

Other navigation apps

City guide apps (e.g. FourSquare®)

Visual identification apps

Public transport/taxi apps

25

$6(23,1)$

$3(11,5)$

\section{5}

25
25

$4(15,4)$

$4(15,4)$

$1(3,8)$

$7(26,9)$

$4(15,4)$

$7(26,9)$

$3(11,5)$

$5(19,2)$

$2(7,7)$

$9(34,6)$

$1(3,8)$

Other

24

25

Running errands

Navigation apps designed for people with

VI (e.g. BlindSquare $®)$

Other navigation apps

City guide apps (e.g. FourSquare $\left.{ }^{\circledR}\right)$

Barcode and $\mathrm{QR}$ code reader apps

Text reading apps

Visual identification apps

Service apps (e.g. mobile bank,

appointments, public transport etc.)

Social media

Be My Eyes $®$ app

25

24

24

24

24
24

24
24

$7(26,9)$

$3(11,5)$

$5(19,2)$

0

$4(15,4)$

$7(26,9)$

$7(26,9)$

$6(23,1)$

$9(34,6)$

23

$8(30,8)$

$1(3,8)$

$13,8)$
0

$4(15,4)$

$1(3,8)$

$5(19,2)$

$1(3,8)$

0

$1(3,8)$

0

$1(3,8)$

$3(11,5)$

$2(7,7)$

$1(3,8)$
$2(7,7)$

$2(7,7)$

$1(3,8)$

$1(3,8)$

$2(7,7)$

$2(7,7)$
$1(3,8)$

$3(11,5)$

$3(11,5)$
$2(7,7)$

$1(3,8)$

$2(7,7)$

25
6

\section{Leisure time}




\begin{tabular}{|c|c|c|c|c|c|c|c|}
\hline $\begin{array}{l}\text { Navigation apps designed for people with } \\
\left.\text { VI (e.g. BlindSquare }{ }^{\circledR}\right)\end{array}$ & 26 & $5(19,2)$ & $3(11,5)$ & $2(7,7)$ & $3(11,5)$ & $2(7,7)$ & $11(42,3)$ \\
\hline Other navigation apps & 26 & $5(19,2)$ & $1(3,8)$ & $4(15,4)$ & $2(7,7)$ & $9(34,6)$ & $5(19,2)$ \\
\hline City guide apps (e.g. FourSquare $\left.{ }^{\circledR}\right)$ & 26 & $8(30,8)$ & $2(7,7)$ & $1(3,8)$ & 0 & $1(3,8)$ & $14(53,8)$ \\
\hline Text reading apps & 25 & $6(23,1)$ & $2(7,7)$ & $1(3,8)$ & $1(3,8)$ & $1(3,8)$ & $14(53,8)$ \\
\hline Visual identification apps & 26 & $7(26,9)$ & $2(7,7)$ & $1(3,8)$ & $1(3,8)$ & 0 & $15(57,7)$ \\
\hline Luetus ${ }^{\circledR}$ (journal app designed for people with VI) & 26 & $3(11,5)$ & $1(3,8)$ & $3(11,5)$ & $3(11,5)$ & $9(34,6)$ & $7(26,9)$ \\
\hline Other journal apps & 26 & $5(19,2)$ & $1(3,8)$ & $3(11,5)$ & $4(15,4)$ & $6(23,1)$ & $7(26,9)$ \\
\hline $\begin{array}{l}\text { Service apps (e.g. mobile bank, appointments, public } \\
\text { transport etc.) }\end{array}$ & 25 & $3(11,5)$ & 0 & $2(7,7)$ & $4(15,4)$ & $13(50,0)$ & $3(11,5)$ \\
\hline Social media & 25 & $7(26,9)$ & $1(3,8)$ & $2(7,7)$ & $4(15,4)$ & $8(30,8)$ & $3(11,5)$ \\
\hline E-mail & 26 & $4(15,4)$ & $1(3,8)$ & 0 & $4(15,4)$ & $15(57,7)$ & $2(7,7)$ \\
\hline Entertainment apps designed for people with VI & 25 & $8(30,8)$ & $1(3,8)$ & 0 & $2(7,7)$ & $2(7,7)$ & $12(46,2)$ \\
\hline Other entertainment apps & 25 & $3(11,5)$ & $1(3,8)$ & $4(15,4)$ & $7(26,9)$ & $8(30,8)$ & $2(7,7)$ \\
\hline Game apps & 26 & $13(50,0)$ & $2(7,7)$ & $4(15,4)$ & $1(3,8)$ & $1(3,8)$ & $5(19,2)$ \\
\hline Other & 6 & $1(3,8)$ & 0 & 0 & $1(3,8)$ & 0 & $4(15,4)$ \\
\hline
\end{tabular}

